\title{
Classification of Functional Psychoses and Its Implication for Prognosis: Comparison between ICD-10 and DSM-IV
}

\author{
Markus Jäger Ronald Bottlender Anton Strauss Hans-Jürgen Möller \\ Department of Psychiatry, Ludwig-Maximilians University, Munich, Germany
}

\author{
Key Words \\ DSM-IV · ICD-10 · Diagnoses · Course · Functional \\ psychoses $\cdot$ Follow-up
}

\begin{abstract}
Background: The aim was to examine the agreement and differences between ICD-10 and DSM-IV in the classification of functional psychoses. Sampling and Methods: In a sample of 218 first-hospitalised patients, ICD-10 diagnoses were compared with DSM-IV diagnoses. Functional psychoses of both diagnostic systems were classified into the four diagnostic groups schizophrenia, transient/episodic psychoses, delusional disorders and affective disorders. Based on information from a 15-year follow-up, it was examined which course is associated with each diagnostic group. Results: Although in ICD-10 there was a higher frequency of schizophrenia and a lower one of affective disorders, a high agreement between ICD-10 and DSM-IV (kappa value of 0.82) was found. In both diagnostic systems, transient/episodic psychoses and affective disorders were mainly associated with a non-chronic course and schizophrenia was mainly associated with a chronic one. Nevertheless, several patients with transient/episodic psychoses showed a chronic course (ICD-10: 10\%, DSM-IV: 15\%) and more than one third of patients with schizophrenia a non-chronic one
\end{abstract}

(ICD-10: 40\%, DSM-IV: 33\%). Conclusions: In the crosssectional assessment, there is a high diagnostic agreement between ICD-10 and DSM-IV. With respect to the long-term course, the delimitation of transient/episodic psychoses from schizophrenia was neither completely achieved by ICD-10 nor by DSM-IV.

Copyright $\odot 2004$ S. Karger AG, Basel

\section{Introduction}

In their article 'Establishment of diagnostic validity in psychiatric illness: Its application to schizophrenia', Robins and Guze [1] described a strategy for achieving diagnostic validity in psychiatric illness founded upon an empirical database. For this purpose, they proposed a 5point model: clinical description, laboratory studies, delimitation from other disorders, follow-up studies and family studies. The idea to constitute diagnostic entities with regard to course and outcome was introduced by Kraepelin [2]. He divided functional, i.e. non-organic, psychoses into the two main groups 'dementia praecox', which he related to an unfavourable course, and 'manicdepressive insanity', which he associated with a favourable one. Furthermore, 'paranoia', Kraepelin's term for psychoses with mere delusional symptoms, was also associated with an unfavourable course. However, based on

\section{KARGER \\ Fax +41613061234 \\ E-Mail karger@karger.ch \\ www. karger.com \\ (C) 2004 S. Karger AG, Basel \\ 0254-4962/04/0373-0110\$21.00/0 \\ Accessible online at: \\ www. karger.com/psp}

Markus Jäger, MD

Department of Psychiatry, Ludwig-Maximilians University, Nussbaumstrasse 7

DE-80336 München (Germany)

Tel. +498951602773, Fax +498951605875

E-Mail markus.jaeger@psy.med.uni-muenchen.de 
the experience that some cases with prominent psychotic symptoms typical for 'dementia praecox' are associated with a favourable course typical for 'manic-depressive insanity', Kraepelin's classification was expanded by concepts such as 'schizoaffective psychosis' [3], 'schizophreniform psychosis' [4], 'cycloid psychosis' [5, 6] or 'reactive psychosis' [7, 8]. In spite of several differences, all these diverse concepts aimed at the delimitation of benign psychotic disturbances with a remitting course from chronic schizophrenic disorders [9, 10]. Robins and Guze [1] also pleaded for a differentiation between 'good prognosis schizophrenia' according to the concepts mentioned above and 'poor prognosis schizophrenia', as these were considered to be two separate diagnostic entities.

The publication by Robins and Guze [1] stimulated the development of DSM-III, which was followed by DSM-III-R, ICD-10 and DSM-IV. These operationalised diagnostic systems have allowed to achieve a common and internationally accepted diagnostic language in psychiatry [11]. However, there is some competition between the two current diagnostic systems ICD-10 [12] and DSM-IV [13]. Both are founded upon the traditional concepts of functional psychoses: with the diagnostic groups schizophrenia, affective disorders and delusional disorders, both diagnostic systems have their historical roots in Kraepelin's classification. However, these diagnostic groups are operationalised in different ways. Furthermore, according to 'good prognosis schizophrenia' by Robins and Guze [1], there are further diagnostic entities in both ICD-10 (e.g. acute and transient psychotic disorders, schizoaffective disorders) and DSM-IV (e.g. schizophreniform disorders, brief psychotic disorders, schizoaffective disorders).

Until now the agreement between both diagnostic systems has been unclear. There is only a small amount of empirical data available to answer the question whether there are substantial differences between ICD-10 and DSM-IV, or whether both diagnostic systems are largely comparable [14-16]. However, this question is important because some of the current studies on epidemiology and therapy refer to ICD-10 and the others to DSM-IV. Furthermore, there is the question as to which course and outcome is associated with the various diagnostic groups in ICD-10 and DSM-IV and whether differences between ICD-10 and DSM-IV may have prognostic implications.

In the present study, the agreement between the classification of functional psychoses in ICD-10 and those in DSM-IV is investigated in a sample of first-hospitalised patients which was followed up for 15 years. In particular, the aim of the present study was to answer the following questions: (1) Is there a high or a low diagnostic agreement between ICD-10 and DSM-IV in the cross-sectional assessment of functional psychoses at first hospitalisation? (2) Which long-term course is associated with the diagnostic groups in ICD-10 and DSM-IV?

\section{Methods}

\section{Selection of Patient Sample}

The sample stems from Munich and surroundings and includes all psychiatric in-patients (consecutive admissions), who were first admitted to the psychiatric hospital of the Ludwig-Maximilians University, Munich, between January 1, 1980 and December 31, 1981, suffering from a functional psychosis (ICD-9: 295.x, 296.x, 297.x, 298.x). Subjects were excluded if they had a history of major medical illness, head injury or symptoms of drug or alcohol dependence at the time of psychiatric admission. In total, 218 patients, 63 men (33.2 years, $\mathrm{SD}=13.8)$ and 155 women $(38.3$ years, $\mathrm{SD}=13.6)$ were enrolled in the study. Patients gave their informed consent.

From the total sample $(\mathrm{n}=218)$, follow-up information was available for 201 persons. Twenty-four persons refused to provide detailed follow-up data. Thus, the only information available for these patients was that they are alive. Twenty-seven persons were known to be deceased. In 25 persons, a complete follow-up examination (faceto-face interview) was impossible for different reasons (e.g. permanent residence in a foreign country). There were no significant differences in baseline variables such as age, gender and frequency of diagnostic groups between the sample with complete follow-up data $(\mathrm{n}=$ $125)$ and those patients with incomplete $(n=76)$ or missing $(n=17)$ follow-up data.

\section{Diagnoses at First Hospitalisation and Comparison between}

DSM-IV and ICD-10

All patients were rediagnosed on the basis of their clinical case records from first hospitalisation by applying operational diagnostic criteria according to ICD-10 [12] and DSM-IV [13]. Based upon the information available at the time of first hospitalisation diagnoses were made by two well-experienced psychiatrists. Both raters were blinded to the results of the follow-up examination. This procedure was made possible by the great amount of detailed information routinely included in the clinical case records of the psychiatric hospital of the Ludwig-Maximilians University. Application of operational diagnostic criteria to clinical case records is a commonly used procedure in psychiatric research $[17,18]$.

In order to compare ICD-10 diagnoses with those of DSM-IV, functional psychoses were divided into the four diagnostic metagroups schizophrenia, transient/episodic psychoses, delusional disorders and affective disorders, all of which are defined in the operationalisation of both ICD-10 and DSM-IV (table 1).

Due to the low frequency of respective diagnoses and the lack of corresponding categories in ICD-10 and DSM-IV, the diagnostic meta-group called 'transient/episodic psychoses' was introduced. This meta-group refers to diagnostic concepts that are denoted as 'good prognosis schizophrenia' by Robins and Guze [1] or 'remitting atypical psychosis' by Menuk et al. [9] and that appear in different terms in ICD-10 and DSM-IV (table 1). In this context, Jablensky [19] has pointed out that the existence of a group of 'non-schizophrenic psychotic disorders' that are symptomatically and prognosti- 
Table 1. Definitions of the corresponding diagnostic groups in ICD-10 and DSM-IV

\begin{tabular}{|c|c|c|}
\hline Diagnostic group & ICD-10 diagnosis & DSM-IV diagnosis \\
\hline Schizophrenia & Schizophrenia $(n=62):$ F20 & Schizophrenia $(\mathrm{n}=50): 295.1,2,3,6,9$ \\
\hline \multirow[t]{4}{*}{ Transient/episodic psychoses } & Acute and transient psychotic disorders $(\mathrm{n}=31)$ : F23 & Schizophreniform disorders $(n=23): 295.40$ \\
\hline & Schizoaffective disorders $(n=19):$ F25 & Brief psychotic disorders $(n=11): 298.80$ \\
\hline & & Schizoaffective disorders $(n=6): 295.70$ \\
\hline & & Psychotic disorders NOS $(n=6): 298.90$ \\
\hline Delusional disorders & Delusional disorders $(\mathrm{n}=20)$ : F22 & Delusional disorders $(n=23): 297.10$ \\
\hline Affective disorders & Affective disorders $(\mathrm{n}=86)$ : F30, F31, F32, F33 & Affective disorders ( $\mathrm{n}=99): 296$ \\
\hline
\end{tabular}

cally different from schizophrenia and affective disorders is supported by clinical and epidemiological evidence.

Cohen's kappa [20] was used to analyse the diagnostic agreement between ICD-10 and DSM-IV. With this procedure, it is possible to prove the amount of agreement between the two diagnostic systems. The kappa value is defined not simply as the fraction of agreement but rather as the fraction of agreement corrected for chance. Thus, a kappa value close to 1 indicates a near-perfect agreement, while a kappa value near to 0 means not only that agreement is poor, but also that agreement is no greater than would be expected by chance. According to Landis and Koch [21], a kappa value higher than 0.80 indicates an excellent, a kappa value between 0.61 and 0.80 a good and a value between 0.41 and 0.61 a moderate agreement.

\section{Fifteen-Year Follow-Up and Association of Diagnostic Groups} with the Long-Term Course

According to Feinstein [22], who applied his well-known taxonomic views on psychiatric context, course and outcome are important parameters for the validation of diagnostic entities. Similar ideas were proposed by Goodwin and Guze [23] who in fact intoned 'diagnosis is prognosis'. Following the models of both Kraepelin [2] and Robins and Guze [1], schizophrenia and delusional disorders are associated with an unfavourable course. On the other hand, transient/episodic psychoses and affective disorders are associated with a favourable one.

Several attempts have been made to classify the course and outcome of functional psychoses. In his long-term study, Bleuler [24] divided clinical course into eight types, while Watt et al. [25], in their 5-year follow-up study, described four types of clinical course.

Similar to the latter approach, the course of illness was divided into three clinical types. Based upon the results of the 15-year followup assessment, which included a Global Assessment Scale (GAS) rating [26], these types are operationalised in the following way.

(1) Single episode: there was a complete remission after the index episode. In the further course, there were no symptoms of a functional psychosis.

(2) Episodic-remitting course: in the further course, there were other episodes of functional psychoses. In the 2 years preceding the follow-up examination, the GAS value was not consistently lower than 61 .

(3) Chronic course: there was no complete remission after the index episode and/or further episodes of functional psychoses. In the 2 years preceding the follow-up examination, the GAS value was consistently lower than 61 .
In accordance with Harrison et al. [27], the chronic course was operationalised by considering the GAS rating. Similar methods were applied in the Vermont Longitudinal Study [17] in order to differentiate between a favourable and an unfavourable course. The GAS [26] is an internationally well-known, single-dimension rating scale for the evaluation of the overall psychosocial functioning of a subject on a continuum from severe psychiatric illness to good health. Möller et al. [28] found that the GAS value is appropriate for use as a global outcome parameter and that it shows a high correlation with other cross-sectional outcome dimensions. In the present study, all raters were trained to use the GAS and reached a high interrater reliability [29].

The four diagnostic groups schizophrenia, transient/episodic psychoses, delusional disorders and affective disorders were opposed to the three course types. Group differences between ICD-10 and DSMIV were evaluated using the $\chi^{2}$ test; a $p$ value of $<0.05$ (2-tailed) was considered as statistically significant. Statistical analyses were carried out using the SPSS 7.5 software for Windows.

\section{Results}

\section{Is There a High or a Low Diagnostic Agreement between ICD-10 and DSM-IV in the Cross-Sectional Assessment of Functional Psychoses at First Hospitalisation?}

In order to point out the agreement and differences between both diagnostic systems, diagnostic groups of ICD-10 were opposed to those of DSM-IV in a cross-classified table (table 2). The frequency of diagnostic groups is shown for ICD-10 in the right column and for DSM-IV in the lowest line. A higher frequency of schizophrenia was found in ICD-10 (29\%) than in DSM-IV (23\%). On the other hand, there was a lower frequency of affective disorders in ICD-10 (39\%) than in DSM-IV (45\%). Minor differences between ICD-10 and DSM-IV were found in the diagnostic groups transient/episodic psychoses and delusional disorders.

\footnotetext{
$\overline{112} \quad \overline{\text { Psychopathology 2004;37:110-117 }}$
} 
Table 2. Comparison of the corresponding diagnostic groups in ICD-10 and DSM-IV

\begin{tabular}{lcllll}
\hline & $\begin{array}{l}\text { SCH } \\
\text { DSM-IV }\end{array}$ & $\begin{array}{l}\text { TRA } \\
\text { DSM-IV }\end{array}$ & $\begin{array}{l}\text { DEL } \\
\text { DSM-IV }\end{array}$ & $\begin{array}{l}\text { AFF } \\
\text { DSM-IV }\end{array}$ & $\begin{array}{l}\text { ICD-10 } \\
\text { total }\end{array}$ \\
\hline SCH ICD-10 & 50 & 12 & - & - & $62(29)$ \\
TRA ICD-10 & - & 34 & 3 & 13 & $50(23)$ \\
DEL ICD-10 & - & - & 20 & - & $20(9)$ \\
AFF ICD-10 & - & - & - & 86 & $86(39)$ \\
DSM-IV total & $50(23)$ & $46(21)$ & $23(11)$ & $99(45)$ & $218(100)$ \\
\hline
\end{tabular}

$\mathrm{SCH}=$ Schizophrenia; TRA = transient/episodic psychoses; $\mathrm{DEL}=$ delusional disorders; $\mathrm{AFF}=$ affective disorders. Figures in parentheses indicate percentages.

The four diagonal fields of table 2 show the cases in which ICD-10 diagnoses agree with DSM-IV diagnoses. The fields above and below the diagonal show the divergent cases between diagnostic groups in ICD-10 and DSM-IV. There were only three types of divergence. First, there were 12 cases which were classified in ICD-10 as schizophrenia and in DSM-IV as transient/episodic psychoses. This is because ICD-10 criteria for schizophrenia require a duration of only 1 month, whereas DSM-IV criteria require a duration of at least 6 months. In all of these 12 cases, the duration of illness was more than 1 month and less than 6 months. Second, there were 3 cases of ICD-10 transient/episodic disorders, which belonged to DSM-IV delusional disorders. These differences are based upon the fact that ICD-10 criteria for delusional disorders require a duration of at least 3 months, whereas DSM-IV criteria require a duration of only 1 month. Third, 13 cases of ICD-10 transient/episodic psychoses were classified in DSM-IV as affective disorders. All of these 13 patients had both marked affective symptoms and psychotic features like bizarre delusions, thought insertion or voices conversing with each other. In contrast to ICD-10, those psychotic symptoms are reconcilable with the diagnosis of an affective disorder in DSM-IV.

Table 3 shows the agreement between ICD-10 and DSM-IV measured in the form of kappa values. The total kappa value of 0.82 indicates an excellent agreement. In particular, this is true for schizophrenia $(\mathrm{kappa}=0.86)$, delusional disorders (kappa $=0.92$ ) and affective disorders $(\mathrm{kappa}=0.88)$. This high agreement is due to the fact that, without exception, all cases of DSM-IV schizophrenia were classified as ICD-10 schizophrenia, all cases of ICD-10 delusional disorders were classified as DSM-IV
Table 3. Agreement of the corresponding diagnostic groups in ICD-10 and DSM-IV

\begin{tabular}{ll}
\hline Diagnostic groups & kappa value \\
\hline Schizophrenia & 0.86 \\
Transient/episodic psychoses & 0.63 \\
Delusional disorders & 0.92 \\
Affective disorders & 0.88 \\
Total & 0.82 \\
\hline
\end{tabular}

delusional disorders and all cases of ICD-10 affective disorders were classified as DSM-IV affective disorders.

In contrast to the other diagnostic groups, divergences were found in two directions only for the diagnostic group transient/episodic psychoses (table 2). Apart from the 12 cases, which belonged to DSM-IV transient/episodic psychoses but not to ICD-10 transient/episodic psychoses, there were 16 cases that belonged to ICD-10 transient/ episodic psychoses but not to the corresponding group in DSM-IV. Hence, it is not surprising that the kappa value for transient/episodic psychoses (0.63), although indicating a good agreement, was much lower than for the other three diagnostic groups.

No significant differences were found when each diagnostic group in ICD-10 was compared with the corresponding group in DSM-IV with respect to age and gender. This is not surprising because of the high agreement between the diagnostic groups in ICD-10 and DSM-IV. Therefore, a presentation of these data in detail was renounced.

\section{Which Long-Term Course Is Associated with the}

\section{Diagnostic Groups in ICD-10 and DSM-IV?}

In a second step, using the sample with complete follow-up data $(\mathrm{n}=125)$, it was examined which prognostic implications are associated with the diagnostic groups in ICD-10 and DSM-IV. Therefore, the four diagnostic groups schizophrenia, transient/episodic psychoses, delusional disorders and affective disorders were opposed to the three course types single episode, episodic-remitting course and chronic course (table 4).

Both ICD-10 schizophrenia (60\%) and DSM-IV schizophrenia (67\%) were mainly associated with a chronic course. Differences between ICD-10 and DSMIV were not statistically significant $\left(\chi^{2}=0.429\right.$, d.f. $=2$, $\mathrm{p}=0.807)$. However, in both diagnostic systems, there were many cases with an episodic-remitting course (35\% 
Table 4. Association of diagnostic groups with course types

\begin{tabular}{|c|c|c|}
\hline \multicolumn{3}{|c|}{ Course type } \\
\hline \multicolumn{3}{|l|}{ a ICD-10 } \\
\hline \multirow[t]{3}{*}{$\mathrm{SCH}(\mathrm{n}=37)$} & chronic & $60 \%(n=22)$ \\
\hline & episodic & $35 \%(\mathrm{n}=13)$ \\
\hline & single & $5 \%(\mathrm{n}=2)$ \\
\hline \multirow[t]{3}{*}{ TRA $(n=31)$} & chronic & $10 \%(\mathrm{n}=3)$ \\
\hline & episodic & $68 \%(\mathrm{n}=21)$ \\
\hline & single & $23 \%(\mathrm{n}=7)$ \\
\hline \multirow[t]{3}{*}{$\operatorname{DEL}(n=6)$} & chronic & $33 \%(\mathrm{n}=2)$ \\
\hline & episodic & $67 \%(n=4)$ \\
\hline & single & $0 \%(\mathrm{n}=0)$ \\
\hline \multirow[t]{3}{*}{$\operatorname{AFF}(\mathrm{n}=51)$} & chronic & $4 \%(n=2)$ \\
\hline & episodic & $90 \%(n=46)$ \\
\hline & single & $6 \%(\mathrm{n}=3)$ \\
\hline \multicolumn{3}{|l|}{ b DSM-IV } \\
\hline \multirow[t]{3}{*}{$\mathrm{SCH}(\mathrm{n}=30)$} & chronic & $67 \%(\mathrm{n}=20)$ \\
\hline & episodic & $30 \%(\mathrm{n}=9)$ \\
\hline & single & $3 \%(\mathrm{n}=1)$ \\
\hline \multirow[t]{3}{*}{$\operatorname{TRA}(\mathrm{n}=27)$} & chronic & $15 \%(n=4)$ \\
\hline & episodic & $59 \%(\mathrm{n}=16)$ \\
\hline & single & $26 \%(\mathrm{n}=7)$ \\
\hline \multirow[t]{3}{*}{$\operatorname{DEL}(\mathrm{n}=8)$} & chronic & $25 \%(\mathrm{n}=2)$ \\
\hline & episodic & $63 \%(\mathrm{n}=5)$ \\
\hline & single & $13 \%(\mathrm{n}=1)$ \\
\hline \multirow{3}{*}{$\operatorname{AFF}(n=60)$} & chronic & $5 \%(\mathrm{n}=3)$ \\
\hline & episodic & $90 \%(\mathrm{n}=54)$ \\
\hline & single & $5 \%(\mathrm{n}=3)$ \\
\hline
\end{tabular}

$\mathrm{SCH}=$ Schizophrenia; TRA = transient/episodic psychoses; DEL $=$ delusional disorders; $\mathrm{AFF}=$ affective disorders; chronic $=$ chronic course , episodic $=$ episodic-remitting course $;$ single $=$ single episode .

in ICD-10 and 30\% in DSM-IV). Single episodes were rare both in ICD-10 schizophrenia (5\%) and DSM-IV schizophrenia (3\%).

With regard to transient/episodic psychoses, there were no significant differences either $\left(\chi^{2}=0.546\right.$, d.f. $=2$, $\mathrm{p}=0.761)$ between ICD-10 and DSM-IV. Most cases showed episodic-remitting courses (68\% of ICD-10 transient/episodic psychoses and 59\% of DSM-IV transient/ episodic psychoses). The second most frequent course of transient/episodic psychoses was single episodes (23\% in ICD-10 and 26\% in DSM-IV). Furthermore, there were cases with a chronic course in both ICD-10 transient/episodic psychoses (10\%) and DSM-IV transient/episodic psychoses (15\%).

Contrary to the expectations, ICD-10 delusional disorders were mainly associated with an episodic-remitting course (67\%). Only 33\% were associated with a chronic course. Similarly, DSM-IV delusional disorders were associated with an episodic-remitting course in $63 \%$, with a chronic course in $25 \%$ and with single episodes in $13 \%$. Owing to the low size of this diagnostic group, statistical tests are not meaningful.

In the group of affective disorders, there were only a few, statistically non-significant $\left(\chi^{2}=0.111\right.$, d.f. $=2, p=$ $0.946)$ differences between ICD-10 and DSM-IV. ICD-10 affective disorders showed an episodic-remitting course in $90 \%$, a single episode in $6 \%$ and a chronic course in $4 \%$ of cases. DSM-IV affective disorders are associated with an episodic-remitting course in $90 \%$, with a single episode in $5 \%$ and with a chronic course in $5 \%$ of cases.

\section{Discussion}

The aim of the present study was to examine the agreement and differences between ICD-10 and DSM-IV with respect to the four diagnostic groups schizophrenia, transient/episodic psychoses, delusional disorders and affective disorders. Furthermore, in order to analyse the association of diagnostic groups with long-term course, the four diagnostic groups were opposed to the three course types single episode, episodic-remitting course and chronic course. Diagnoses are based upon the information available at the time of first hospitalisation and course types are based on the information from the follow-up assessment (15 years later).

\section{Schizophrenia}

With respect to schizophrenia, a high diagnostic agreement between ICD-10 and DSM-IV was found (kappa = $0.86)$. The formerly pronounced disproportion between the European and American concept of schizophrenia [30] has obviously been evened out with ICD-10 and DSM-IV. Furthermore, the results of the present study show that in DSM-IV there is a narrower concept of schizophrenia than in ICD-10. This is not surprising because DSM-IV criteria require a duration of at least 6 months for this diagnosis, whereas ICD-10 criteria require a duration of only 1 month. However, these differences seem to have only a low prognostic impact: $60 \%$ of ICD-10 schizophrenia and 67\% of DSM-IV schizophrenia were associated with a chronic course type. The differences were not statistically significant. Thus, the less restrictive 1-month duration criterion of ICD-10 does not implicate a significant loss of predictive validity with respect to the long-term course. Similar conclusions were drawn by Mason et al. [31]. Furthermore, the proportions 
of ICD-10 schizophrenia associated with a chronic course $(60 \%)$ are in line with those reported by Harrison et al. [27] (62.2\%), whose operationalisation of chronic course was adopted in the present study. With respect to prognosis, both ICD-10 schizophrenia and DSM-IV schizophrenia seem to have an intermediate position between Kraepelin's 'dementia praecox', with more than $85 \%$ chronic cases [32], and Bleuler's [24] 'group of schizophrenia', with less than $45 \%$ chronic cases. However, these conclusions are limited by the different definition of 'chronic course' in the respective investigations.

\section{Affective Disorders}

Affective disorders also showed a high agreement between ICD-10 and DSM-IV (kappa = 0.88). However, in DSM-IV, the concept of affective disorders is wider: DSM-IV allows symptoms like 'bizarre delusions' ('thought insertion', 'thought broadcasting', 'delusions of influence') or 'voices conversing with each other' [13], whereas in the ICD-10 those symptoms are not reconcilable with this diagnosis. Results of the follow-up examination revealed that, in spite of expansion of this diagnostic group, in DSM-IV there is no loss of predictive validity in the form of a high association with a quite favourable prognosis: $95 \%$ of DSM-IV affective disorders and $96 \%$ of ICD-10 affective disorders showed an episodic-remitting course or a single episode. These results are in line with those from Pope and Lipinski [33], who reported that 'socalled schizophrenic symptoms' have no prognostic impact, if they are accompanied with affective symptoms.

\section{Delusional Disorders}

Of all diagnostic groups, the highest agreement was found in delusional disorders (kappa $=0.92$ ). The remaining divergences are caused by the fact that DSM-IV requires a duration of only 1 month, whereas ICD-10 requires a duration of at least 3 months. Because of the low number of persons with complete follow-up data, statements about course are limited in this diagnostic group.

\section{Transient/Episodic Psychoses}

The lowest diagnostic agreement between ICD-10 and DSM-IV was found in transient/episodic psychoses (schizoaffective disorders, DSM-IV: 295.70, ICD-10: F25; acute and transient psychotic disorders, ICD-10: F23; schizophreniform disorders, DSM-IV: 295.40; brief psychotic disorders, DSM-IV: 298.80; psychotic disorders NOS (not otherwise specified), DSM-IV: 298.90). Nevertheless, the kappa value of 0.63 still indicates a good agreement. However, this kappa value should not hide the fact that transient/episodic psychoses represent a diagnostic meta-group. This means that there are many differences between ICD-10 and DSM-IV with respect to the terminology of the corresponding diagnostic entities (table 1). For more than 100 years, psychiatrists have known the problem of transient/episodic psychoses. There have been several attempts to comprise cases with prominent psychotic symptoms typical for Bleuler's 'group of schizophrenia' on the one hand and a favourable course typical for Kraepelin's 'manic-depressive insanity' on the other hand to an own diagnostic entity $[1,9,10]$.

The results of the follow-up examination showed that $90 \%$ of ICD-10 transient/episodic psychoses and $85 \%$ of the corresponding diagnostic group in DSM-IV are associated with a non-chronic course (single episode or episodic-remitting course). Differences between ICD-10 and DSM-IV were not statistically significant. However, in both diagnostic systems, transient/episodic psychoses include cases with a chronic course (ICD-10: 10\%, DSM-IV: $15 \%)$. In particular, this seems to be true for schizoaffective disorders according to DSM-IV and DSM-III-R criteria $[34,35]$. Furthermore, diverse authors have pointed out that several patients who were diagnosed at the time of their first hospitalisation with DSM-IV schizophreniform disorders showed a chronic course [36-39]. The same was reported for ICD-10 acute and transient psychotic disorders $[40,41]$. On the other hand, the results of the present studies revealed that in both diagnostic systems schizophrenia includes more than one third of cases with a non-chronic course (ICD-10: 40\%, DSM-IV: 33\%). The latter point was criticised by Susser et al. [42] and Mojtabai et al. [43], who argued that with regard to prognosis the concept of ICD-10 schizophrenia is too wide, because it includes many cases with acute onset and complete remission. The aim of Robins and Guze [1], i.e. to separate 'good prognosis schizophrenia' from 'poor prognosis schizophrenia', was neither completely achieved by ICD-10 nor by DSM-IV.

\section{Limitations and Conclusions}

One important methodical limitation of the present study is that statements with regard to the further course of illness only refer to patients with complete follow-up data. However, with respect to age, gender and frequency of diagnostic groups in ICD-10 and DSM-IV, there are no significant differences between this sample and the sample with missing or incomplete follow-up data. Thus, a selection bias concerning these variables seems improbable. Furthermore, one can criticise the method of retro- 
spective assessment of diagnoses based upon clinical case records, which can cause an overestimation of diagnostic agreement between ICD-10 and DSM-IV. However, such a retrospective diagnostic procedure in the form of consensus diagnosis has the advantage that observer variance is minimised and the remaining differences between ICD10 and DSM-IV mainly result in divergences of diagnostic criteria (criterion variance) [44]. Finally, one can criticise the absence of a multidimensional assessment of outcome. However, the present study followed the pragmatic approach of Watt et al. [25] and divided the long-term course into clinical types. In accordance with other stud- ies [17, 27], the course types were operationalised considering the GAS rating and the GAS value usually shows a high correlation with other cross-sectional outcome dimensions [28].

Taken together, there is a high agreement between ICD-10 diagnoses and DSM-IV diagnoses in the crosssectional assessment of functional psychoses. With regard to the long-term course, there are no marked differences between ICD-10 and DSM-IV. However, with respect to the long-term course, the delimitation of transient/episodic psychoses from schizophrenia was neither completely achieved by ICD-10 nor by DSM-IV.

\section{References}

1 Robins E, Guze SB: Establishment of diagnostic validity in psychiatric illness: Its application to schizophrenia. Am J Psychiatry 1970;126: 983-987.

2 Kraepelin E: Psychiatrie, ed 6. Leipzig, Barth, 1899.

3 Kasanin J: The acute schizoaffective psychoses. Am J Psychiatry 1933;13:97-126.

4 Langfeld G: The Schizophreniform States. Copenhagen, Munskgaard, 1939.

5 Leonhard K: Die Aufteilung der endogenen Psychosen. Berlin, Akademie, 1957.

6 Sigmund D, Mundt C: The cycloid type and its differentiation from core schizophrenia: A phenomenological approach. Compr Psychiatry 1999:40:4-18.

7 Strömgren E: The development of the concept of reactive psychoses. Psychopathology 1987; 20:62-70

8 Wimmer A: Psykogene Sindssygdomsformer; in Wimmer A (ed): St Hans Hospital 18161915. Jubilaeumsskrift Kobenhavn. Copenhagen, GEC Grad Publishers, 1916, pp 85-216.

9 Menuk M, Legault S, Schmidt P, Remington $\mathrm{G}$ : The nosological status of the remitting atypical psychoses. Compr Psychiatry 1989;30:5373.

10 Jäger M, Bottlender R, Strauss A, Möller HJ: On the descriptive validity of ICD-10 schizophrenia: Empirical analyses in the spectrum of non-affective functional psychoses. Psychopathology 2003;36:152-159.

11 Mundt C: Common language and local diversities of psychopathological concepts - Alternatives or complements. Psychopathology 2003; 36:111-113.

12 World Health Organization: ICD-10 Classification of Mental and Behavioural Disorders. Diagnostic Criteria for Research. Geneva, World Health Organization, 1993.

13 American Psychiatric Association: Diagnostic and Statistical Manual of Mental disorders, ed 4 (DSM-IV). Washington, American Psychiatric Association, 1994.
14 Andrews G, Slade T, Lorna P: Classification in psychiatry: ICD-10 versus DSM-IV. Br J Psychiatry 1999;174:3-5.

15 Bertelsen A: Schizophrenia and related disorders: Experience with current diagnostic systems. Psychopathology 2002;35:89-93.

16 Paykel ES: Mood disorders: Review of current diagnostic systems. Psychopathology 2002;35: 94-99.

17 Harding CM, Brooks GW, Ashikaga T, Strauss JS, Breier A: The Vermont Longitudinal Study of persons with severe mental illness. 1. Methodology, study sample, and overall status 32 years later. Am J Psychiatry 1987;144:718726.

18 Harding CM, Brooks GW, Ashikaga T, Strauss JS, Breier A: The Vermont Longitudinal Study of persons with severe mental illness. 2. Longterm outcome of subjects who retrospectively met DSM-III criteria for schizophrenia. Am J Psychiatry 1987;144:727-735.

19 Jablensky A: Classification of nonschizophrenic psychotic disorders: A historical perspective. Curr Psychiatry Rep 2001;3:326-331.

20 Cohen J: A coefficient of agreement for nominal scales. Educ Psychol Meas 1960;20:37-46.

21 Landis JR, Koch GG: The measurement of observer agreement for categorical data. Biometrics 1977;33:159-174.

22 Feinstein AR: A critical overview of diagnosis in psychiatry; in Rakoff VM, Gorman H, Kedward HB, Preston AJ, Stancer HC (eds): Psychiatric Diagnosis. New York, Brunner, 1977. pp 189-206.

23 Goodwin DW, Guze SB: Psychiatric Diagnosis. New York, Oxford University Press, 1984.

24 Bleuler M: Die schizophrenen Geistesstörungen im Licht langjähriger Kranken- und Familiengeschichten. Stuttgart, Thieme, 1972.

25 Watt DC, Katz K, Shepherd M: The natural history of schizophrenia. A 5-year prospective follow-up of a representative sample of schizophrenics by means of a standardized clinical and social assessment. Psychol Med 1983;13: 663-670.
26 Endicott J, Spitzer RL, Fleiss JL, Cohen J: The global assessment scale. A procedure for measuring overall severity of psychiatric disturbance. Arch Gen Psychiatry 1976;33:766-771.

27 Harrison G, Hopper K, Craig T, Laska E, Siegel C, Wanderling J, Dube KC, Ganev K, Giel $\mathrm{R}$, an der Heiden W, Holmberg SK, Janca A, Lee PWH, León CA, Malhotra S, Marsella AJ, Nakane Y, Sartorius N, Shen Y, Skoda C, Thara R, Tsirkin SJ, Varma VK, Walsch D, Wiersma D: Recovery from psychotic illness: A 15 and 25-year international follow-up study. Br J Psychiatry 2001;178:506-517.

28 Möller HJ, Hohe-Schramm M, Cording-Tömmel C, Schmid-Bode W, Wittchen HU, Zaudig M, v. Zerssen D: The classification of functional psychoses and its implications for prognosis. Br J Psychiatry 1989; 154:467-472.

29 Möller HJ, Bottlender R, Gross A, Hoff P, Wittmann J, Wegner U, Strauss A: The Kraepelinian dichotomy: Preliminary results of a 15-year follow-up study on functional psychoses: Focus on negative symptoms. Schizophr Res 2002;56:87-94

30 Cooper JE, Kendell RE, Gurland BJ, Sharpe L, Copeland JRM, Simon R: Psychiatric Diagnosis in New York and London. London, Oxford University Press, 1972.

31 Mason P, Harrison G, Croudace T, Glazebrook C, Medley I: The predictive validity of a diagnosis of schizophrenia: A report from the International Study of Schizophrenia (ISoS) coordinated by the World Health Organization and the Department of Psychiatry, University of Nottingham. Br J Psychiatry 1997;170:321327.

32 Kraepelin E: Psychiatrie, ed 8. Leipzig, Barth, 1909-1913.

33 Pope HG, Lipinski JF: Diagnosis in schizophrenia and manic-depressive illness: A reassessment of the specificity of 'schizophrenic' symptoms in the light of current research. Arch Gen Psychiatry 1978;35:811-828. 
34 Tsuang D, Coryell W: An 8-year follow-up of patients with DSM-III-R psychotic depression, schizoaffective disorder and schizophrenia. Am J Psychiatry 1993;150:1182-1188.

35 Strakowski SM, Keck PE, Sax KW, McElroy SL, Hawkin JM: Twelve-month outcome of patients with DSM-III-R schizoaffective disorder: Comparison to matched patients with bipolar disorder. Schizophr Res 1999;35:167174.

36 Strakowski SM: Diagnostic validity of schizophreniform disorder. Am J Psychiatry 1994; 151:815-824.

37 Casachia M, de Cataldo S, Roncone R, Marcelli G: Schizophreniform disorder: A 1-year follow-up study. Psychopathology 1996;29:104108.
38 Zarate CA Jr, Tohen M, Land ML: First-episode schizophreniform disorder: Comparisons with first-episode schizophrenia. Schizophr Res 2002;46:31-34.

39 Naz B, Bromet EJ, Mojtabai R: Distuingishing between first-admission schizophreniform disorder and schizophrenia. Schizophr Res 2003; 62:51-58.

40 Jorgensen P, Bennedsen B, Christensen J, Hyllested A: Acute and transient psychotic disorder: A 1-year follow-up study. Acta Psychiatr Scand 1997;96:150-154.
41 Jäger M, Hintermayr M, Bottlender R, Strauss A, Möller HJ: Course and outcome of firstadmitted patients with acute and transient psychotic disorders (ICD-10:F23): Focus on relapses and social adjustment. Eur Arch Psychiatry Clin Neurosci 2003;253:209-215.

42 Susser E, Varma VK, Matoo SK, Finnerty M, Mojtabai R, Tripathi BM, Misra AK, Wig NN: Long-term course of acute brief psychosis in a developing country setting. Br J Psychiatry 1998;173:226-230.

43 Mojtabai R, Varma VK, Susser E: Duration of remitting psychosis with acute onset. Implications for ICD-10. Br J Psychiatry 2000;176: 576-580.

44 Spitzer RL, Fleiss JL: A re-analysis of the reliability of psychiatric diagnosis. Br J Psychiatry 1975; 125:341-347. 